\title{
PRESENÇA SOCIAL EM CURSOS A DISTÂNCIA: UM ESTUDO COMPARATIVO DE POSTAGENS EM CHATS E FÓRUNS
}

\author{
Helvia Pereira Pinto Bastos, IFF, helviabastos@yahoo.com.br \\ Magda Bercht, UFRGS, bercht@inf.ufrgs.br \\ Leandro Krug Wives, UFRGS, wives@inf.ufrgs.br
}

\section{Resumo}

Trata-se de um estudo de caso feito em chats e fóruns no "Curso de Informática Instrumental para Professores do Ensino Básico" oferecido pelo convênio UAB-IIUFRGS. A pesquisa buscou verificar como os usuários expressam sua presença social o sentimento de estar junto com outros no ambiente virtual - por meio de suas escolhas lexicogramaticais e por signos lingüísticos típicos do discurso em meio eletrônico. A análise das interações foi feita com base nos critérios de afetividade, interatividade, coesão e intensidade. Verificou-se que ambas as ferramentas de comunicação apresentam ocorrências discursivas semelhantes e que estas permitem aos sujeitos evidenciarem sua participação nos eventos de interação em cursos a distância.

Palavras-Chave: Presença Social, Comunicação Mediada por Computador, Educação a Distância, Chats e Fóruns Educacionais.

\begin{abstract}
This paper presents a study of discursive interactions in chats and discussion forums. The aim of the observation was to verify how users express their social presence - the perception of being with others in virtual environments - through the analysis of their lexico-grammatical choices, and the typical linguistic features of the electronic discourse. The study of the interactions was based on affective, interactive, cohesive and intensive discursive aspects. Results show that both communication tools present similar amount and types of occurrences, and that these allow individuals to make themselves more visible in distance education activities.
\end{abstract}

Key-Words: Social Presence, Computer-Mediated Communication, Distance Education, Educational Chats and Forums.

\section{Introdução}

As ferramentas de Comunicação Mediada por Computador (CMC) na Educação a Distância são recursos que possibilitam maior interação entre os alunos, e entre esses e seus tutores. Esses recursos contribuem, assim, para o desenvolvimento dos relacionamentos, colaborando, também, para a retenção do aluno no ambiente (MARTINEZ, 2003). 
Não tendo os recursos da comunicação presencial (gestos, expressão facial, entonação, etc.), os usuários de fóruns e chats se apropriam dos recursos gráficos e hipermidiáticos do computador para (re)criar formas e códigos lingüísticos diferenciados para assinalar, com maior ou menor intensidade, sua presença e pertencimento no grupo e melhor perceberem as intenções de seus interlocutores.

O estudo trata, portanto, da noção de "presença social" manifesta por alunos em seus intercâmbios por escrito. O conceito de presença social (PS) usado neste nesta pesquisa é encontrado em Garrison et alli (1990, 1991, 2001), em que PS é tida como a capacidade do indivíduo em se projetar social e afetivamente em ambientes virtuais.

Com o objetivo de ilustrar como a PS se evidencia nas postagens feitas em Ambientes Virtuais de Ensino e Aprendizagem (AVEAs), este trabalho descreve, na Seção 2, a relevância desse aspecto na formação do sentimento de pertencimento em comunidades de aprendizagem. A Seção 3 fornece, por sua vez, exemplos extraídos do curso observado e sistematizados conforme os critérios de Rourke e colaboradores (2001) e Martin e White (2005), e apresenta uma análise qualitativa dos dados obtidos na observação.

Os autores destacam que o tema deste trabalho é parte do estudo em desenvolvimento no Grupo de Pesquisa em Computação Afetiva Aplicada à Educação (GCAE), vinculado ao Programa de Pós-Graduação em Informática na Educação da Universidade Federal do Rio Grande do Sul.

\section{Presença social na Educação a Distância}

Para Recuero (2001), os AVEAs devem funcionar como "comunidades", espaços que devem fomentar o sentimento de pertencimento - descrito pela autora como "a noção de que o indivíduo é parte do todo, coopera para uma finalidade comum com os demais membros [...]. Pertencimento e presença social constituem noções semelhantes, consideradas relevantes na observação de como os alunos se projetam nas interações via CMC e na manutenção desses sujeitos em cursos a distância (PALLOFF e PRATT, 2002, 2004). As pesquisas sobre presença social e sua relação com as diferentes mídias se iniciaram ainda antes do advento das Tecnologias da Informação e da Comunicação, como explicado a seguir.

A "Teoria da Presença Social", elaborada por Short, William e Christie (1976) discute o "grau de presença" proporcionado pelos meios de comunicação de massa (mass media). Nesse trabalho, os meios foram classificados como tendo alto grau de presença (p.ex. vídeo) ou baixo grau de presença (p.ex. áudio). Posteriormente, no contexto da Comunicação Mediada por Computador (CMC), diferentes estudos sustentaram que as interações baseadas em texto são menos pessoais e "inferiores" do que as feitas face a face $(\mathrm{FaF})$ devido à ausência de sinais não-verbais - expressões faciais e gestuais, articulações sonoras, distância entre os falantes. Nessa perspectiva, os estudos iniciais sobre aprendizagem assistida por computador sofreram críticas porque considerava-se que a falta de ausência de pistas sociais (social cues) interferiam na experiência educativa (Lowenthal, 2009).

Por sua vez, a "Teoria do Processamento Social" de Walther (1992) fornece uma visão oposta ao afirmar que tanto as interlocuções realizadas por meio de ferramentas de 
$\mathrm{CMC}$ quanto as feitas em situações face a face $(\mathrm{FaF})$ possibilitam o desenvolvimento de relacionamentos, e que os sujeitos podem formar impressões sobre os outros com base apenas no conteúdo lingüístico de suas mensagens. Para Walther (1996), ao suprirem a falta de pistas sociais com recursos hipermidiáticos e / ou discursivos dados pelo computador, os sujeitos acabam por formar o que ele denomina de "relações hiperpessoais", ou seja, com alto nível de presença social.

Walther (1992) explica também que, em meio digital, os sujeitos têm maior liberdade para elaborar seu discurso porque não se sentem constrangidos pela proximidade física de seu(s) interlocutore(s). Isso possibilita que escolham o quê e como querem revelar para os demais e, assim, estabelecer uma imagem social favorável para atrair e manter a atenção sobre si. Por outro lado, o autor destaca que os receptores, por vezes, criam uma imagem idealizada de seu(s) interlocutor(es), supervalorizando as pistas textuais disponíveis.

Gunawardena (1995) defende a idéia de que a forma como os sujeitos percebem a própria presença ou a dos outros tem maior peso do que o meio de comunicação em si. Para a autora, a CMC não tem nível inferior de pistas sociais, sendo, ao contrário, um meio "estimulante, interessante e interativo", que pode, dependendo da atuação dos modiadores, promover senso de comunidade e aprendizagem do tipo cooperativa / colaborativa.

Por essa razão, autores como Palloff e Pratt (2002, 2004), Mackey e Freyberg (2010), orientam que os AVEAs devem promover ações que favoreçam o "estar junto virtual" e o sentimento de pertença e presença social. Segundo Garrison (1990), a interação entre os aprendizes, e entre estes com seus tutores, resulta em maior motivação e experiências de aprendizagem mais produtivas.

Dessa forma, o levantamento de marcas lexicais indicadores de PS implica, também, na verificação simultânea de como o aluno manifesta, discursivamente, sua afetividade para com os diferentes aspectos do AVEA. Neste estudo, usamos o termo afetividade na acepção de Bercht (2001, pg. 59), em que o termo se refere ao "domínio das emoções propriamente ditas, dos sentimentos, das emoções, das experiências sensíveis e, principalmente, da capacidade em se poder entrar em contato com sensações".

Em seu estudo sobre a percepção de presença social (PS) em discussões assíncronas feitas em AVEAs, Shih e Swan (2009) concluem que a PS pode e deve ser fomentada, por exemplo, por um planejamento cuidadoso das discussões, da conscientização de alunos e tutores de como seu discurso amplia ou restringe sua presença e envolvimento no grupo. Os autores destacam que fóruns educacionais com muitas instâncias de interatividade discursiva podem auxiliar certos alunos a se adaptar ao processo de ensino e aprendizagem a distância.

Um modelo teórico fundador da noção de presença em experiências de aprendizagem em meio eletrônico é o Community of Inquiry - Comunidade de Investigação (Garrison, 1991), fundamentado no princípio de que a "experiência de aprendizagem" deve envolver o desenvolvimento e integração de três tipos de presença: (i) cognitiva (relativa ao como o aprendiz constrói significados por meio de comunicação mediada por tecnologias), (ii) docente (relativa à preparação e gestão das sequências didáticas, dos conteúdos e recursos do AVEA) e, (iii) social (relativa à projeção afetiva e social do aprendiz no ambiente).

Neste estudo, o mapeamento de pistas discursivas denotadoras de PS em intercâmbios realizados em chats e fóruns utiliza as categorias indicadas por Rourke et 
al. (2001) listadas no quadro abaixo, acrescidas do subcampo "Força" (sinalizadora de intensidade) encontrado no Sistema de Avaliatividade Lingüística (Appraisal System) de Martin e White (2005).

Quadro 1 - Critérios de verificação de Presença Social em interações discursivas em AVEAs (adaptado de Rourke et al., 2001 e Martin e White, 2005)

\begin{tabular}{|l|l|}
\hline \multicolumn{1}{|c|}{ CATEGORIA } & \multicolumn{1}{c|}{ INDICADORES } \\
\hline Aspectos afetivos & $\begin{array}{l}\text { Expressão de emoção, utilização de humor, ironia, demonstração de } \\
\text { vulnerabilidade, }\end{array}$ \\
\hline Aspectos interativos & $\begin{array}{l}\text { Participação contínua numa discussão, referência explícitas a outras } \\
\text { postagens, encorajamento, apreciação e concordância }\end{array}$ \\
\hline Aspectos coesivos & $\begin{array}{l}\text { Expressões fáticas e termos de sociabilidade, referência a outros pelo } \\
\text { nome próprio ou pronomes, vocativos }\end{array}$ \\
\hline Força & $\begin{array}{l}\text { Adjetivos e advérbios de intensidade; prefixos e sufixos aumentantivos e } \\
\text { diminutivos, metáforas e analogias }\end{array}$ \\
\hline
\end{tabular}

\subsection{Os Gêneros Textuais Chat e Fórum}

Os chats e fóruns são gêneros textuais digitais - formas lingüísticas independentes e inovadoras que coabitam ou se mesclam com outras convencionais no espaço digital. Segundo Marcuschi (2004, p. 19), os gêneros textuais digitais (emergentes, como os denomina) são híbridos porque além de reproduzirem aspectos constitutivos dos gêneros tradicionais, também apresentam inúmeras marcas de oralidade. Conforme o autor (2001), fala e escrita não constituem dicotomias explícitas, já que ambas apresentam aspectos em comum, a saber: dialogicidade, dinamicidade, estratégias comunicativas, envolvimento, negociação e coerência.

Chamada comumente de internetês, a linguagem usada em chats e fóruns apresenta características lingüísticas diferenciadas, resultantes dos aspectos tipificadores dessas ferramentas de comunicação síncrona e assíncrona. Segundo Othero (2002, p. 23): "Uma nova forma de escrita característica dos tempos digitais foi criada. Frases curtas e expressivas, palavras abreviadas ou modificadas para que sejam escritas no menor tempo possível [...]". São exemplos do internetês: supressão ou uso exagerado de maiúsculas, supressão ou troca de fonemas, uso exagerado de pontuação, substituição do acento gráfico por vogais, onomatopéias expressas pela repetição de consoantes, uso de recursos não-verbais como emoticons, inserção de imagens e áudio. Em geral, esses neologismos são mais recorrentes no gênero chat devido ao fato de ser uma "conversa" em tempo real, apresentando, por isso, frases curtas e inacabadas, além de um registro lingüístico mais informal do que o fórum.

A análise textual de eventos comunicativos (face a face ou via CMC) envolve a observação de quatro aspectos que operam de maneira integrada e interdependente: língua, sujeito, texto e sentido (Kock, 2009), noções entendidas diferentemente conforme a abordagem teórico-metodológica utilizada. Na concepção interacionista indicada por Kock (op.cit.), a produção de sentidos implica a mobilização da seguinte 
tríade: o produtor / planejador, o texto, e o leitor / ouvinte que, de forma conjunta, circulam num contexto. Isso significa, segundo a autora (op.cit., p. 15), que a análise textual precisa considerar os enunciados e não frases isoladas, abstraídas das "condições de produção (quem fala, com quem, quando, onde, em que condições, com que propósitos)".

Portanto, a importância do contexto na estruturação e compreensão dos enunciados é uma questão importante no mapeamento de postagens em ferramentas de CMC, visto que é na seqüência de comentários que os termos ganham sentido. Esse aspecto dialógico do texto encontra respaldo em Bakhtin (1995, p. 113), quando o autor afirma que a palavra é "determinada, tanto pelo fato de que procede de alguém, como pelo fato de que se dirige para alguém. Ela constitui justamente o produto da interação do locutor e do ouvinte".

\section{Contexto da Pesquisa e Coleta de Dados}

As postagens analisadas foram extraídas da disciplina INF010 do "Curso de Especialização em Informática Instrumental para Professores da Educação Básica" (doravante CEII) ${ }^{1}$, oferecido pela Universidade Aberta do Brasil (UAB) e pelo Instituto de Informática e Secretaria de Educação a Distância (SEAD) da Universidade Federal do Rio Grande do Sul. A plataforma de gestão utilizada no curso foi o Moodle.

O curso está sendo ofertado, de forma simultânea, em cinco pólos localizados no Estado do Rio Grande do $\mathrm{Sul}^{2}$, todos equipados com Laboratórios de Informática e constituídos por turmas de 30 alunos cada $u^{3}$. As turmas dispõem de um tutor local para auxílio no acesso aos conteúdos e um tutor remoto para apoio pedagógico. Com duração de 18 meses (2009-2011), o programa apresenta oito disciplinas: Conceitos, Editores, Imagens, Conceitos da Web, Conceitos na Web, Mídias Digitais, Software Educativo, Ambientes de EaD e sua utilização (cada uma subdividida em duas ou três matérias / seções)

Nesse curso, os recursos de comunicação entre os participantes incluem, além de e-mail, encontros em salas de bate-papo e fóruns de discussão, assim caracterizados: (i) Chats de participação eletiva e ofertados semanalmente (1 hora de duração em dia e horário fixos), (ii) Fóruns de Discussão de três tipos: de Dúvidas, de Pólo e de Notícias.

\subsection{Análise dos Resultados}

Os quadros seguintes apresentam exemplos extraídos de 3 fóruns e 5 chats em que os comentários focaram, particularmente, no esclarecimento de dúvidas e compartilhamento de sugestões para resolução de problemas referentes ao cumprimento das tarefas. Os exemplos utilizados mantêm a grafia original e os nomes próprios foram omitidos de forma a não identificar o aluno. 
Destaca-se que um problema encontrado na classificação dos exemplos é o fato de que uma mesma expressão pode ser ilustrativa de mais de um critério. Ilustrando: o termo "BOA NOITE!!!" serve para ilustrar diferentes critérios "uso enfático de maiúsculas", "expressão de afetividade", "pontuação repetida", e "termos de sociabilidade". Por essa razão, a análise textual apresentada neste artigo tem caráter meramente qualitativo.

Quadro 2 - PS no Curso CEII: Pistas textuais indicadoras de Afetividade

\begin{tabular}{|c|c|c|}
\hline INDICADORES & EXEMPLOS FÓRUM & EXEMPLOS CHAT \\
\hline $\begin{array}{l}\text { Expressões de } \\
\text { afetividade }\end{array}$ & $\begin{array}{l}\text { Obrigada pela sua atenção / Agradecido! / Grata } \\
\text { / Agradeço profe!! / Abraços e boa sorte. }\end{array}$ & $\begin{array}{l}\text { Bah! / humm / oi! qto tempo / } \\
\text { arghh e nao ter a nota na hr / } \\
\text { quanto tempo!!! }\end{array}$ \\
\hline $\begin{array}{l}\text { Uso enfático de } \\
\text { maiúsculas }\end{array}$ & $\begin{array}{l}\text { DEVEMOS colocar o ... / DEVO DEIXAR } \\
\text { ESPAÇOS ENTRE AS PALAVRAS (...) / } \\
\text { CONSEGUI enviar o } 1^{\circ} \text { arquivo / PORÉM:... / } \\
\text { DUVIDAS / GRATA / gostaria de uma AJUDA }\end{array}$ & $\begin{array}{l}\text { BOA NOITE!!! / A (...) } \\
\text { FUNCIONA DA MESMA } \\
\text { FORMA DE SEMPRE(...)? / } \\
\text { MELHOR ENTÃO........ }\end{array}$ \\
\hline $\begin{array}{l}\text { Pontuação } \\
\text { repetida }\end{array}$ & $\begin{array}{l}\text { (...) as junções?? Isto gera resultados } \\
\text { diferentes!!! / buscar outros sites?? / será que } \\
\text { entendi!!!! / Abraços!!!!!!! }\end{array}$ & todos os conteúdos??? \\
\hline Emoticons & $69 /$ / $/ ;) /$ & ;) $/=\mathrm{P} /=) /=/ /=\mathrm{x} / \wedge \wedge, / \mathrm{xD} / \Theta$ \\
\hline $\begin{array}{l}\text { Implicâncias, } \\
\text { brincadeiras, } \\
\text { ironia, sarcasmo }\end{array}$ & $\begin{array}{l}\text { Pede ajuda pro Garfield / Desculpem a burrice / } \\
\text { se falei muita bobagem }\end{array}$ & $\begin{array}{l}\text { vamos a luta kkkkk / isso é } \\
\text { disciminação! / achei q nao teria } \\
\text { chat haha primeira vez q entro na } \\
\text { hr e nao tinha ngmmmm / nao ter } \\
\text { a nota na hr... torturante hehe }\end{array}$ \\
\hline $\begin{array}{l}\text { Detalhes da vida } \\
\text { extraclasse }\end{array}$ & $\begin{array}{l}\text { tenho uma colega muito querida / vou viajar a } \\
\text { semana que vem / Estou tendo dificuldades com } \\
\text { meus horários / uso quando necessito acessar } 2 \\
\text { ambientes ao mesmo tempo / Na escola, com os } \\
\text { alunos, aconselho usar o M. Firefox }\end{array}$ & $\begin{array}{l}\text { A Le tb acessou esses dias lá no } \\
\text { Polo / tenho algumas coisinhas } \\
\text { para digitar / é dia letivo o dia } \\
\text { todo na minha escola }\end{array}$ \\
\hline Vulnerabilidade & $\begin{array}{l}\text { tenho dificuldade em encontrar / fiquei com uma } \\
\text { dúvida / Não sei se interpretei corretamente / } \\
\text { fiquei na dúvida / não consegui estabelecer } \\
\text { conclusões / não assimilei... ainda / não entendo } \\
\text { com clareza / estou com medo / Achei muito } \\
\text { difícil }\end{array}$ & $\begin{array}{l}\text { não sei o horário / não entendo / } \\
\text { estou com muita dificuldade / tb } \\
\text { não consegui / não sei se fiz certa } \\
\text { / pq eu to cm duvida nessa }\end{array}$ \\
\hline $\begin{array}{l}\text { Força } \\
\text { (intensidade) }\end{array}$ & $\begin{array}{l}\text { bem mais simples / muito mais rico / nem são } \\
\text { tantos assim / mais fácil que / não parece tão } \\
\text { difícil / quanto mais especifica a pesquisa, } \\
\text { melhores os resultados / uma grande ferramenta } \\
\text { / um tanto complexa / são muitas, são tantas que } \\
\text { não sei se ... / uma espiadinha / difíceis mesmo / } \\
\text { uma vezinha.. / atrapalha bastante }\end{array}$ & $\begin{array}{l}\text { Coisinhas / nao ficou la grande } \\
\text { coisa / um pouco apreensiva / } \\
\text { bem no limite do tempo / bem } \\
\text { legal / uma olhadinha / tá muito } \\
\text { ruim / baixiiiiinhassss / } \\
\text { confundindo um bocado / } \\
\text { absolutamente abrangente / mais } \\
\text { claro }\end{array}$ \\
\hline
\end{tabular}

Os exemplos acima mostram que, como explicado na Seção 2.1., sendo um evento comunicativo síncrono, o chat resulta em um registro mais informal e de menor aprofundamento dos temas das conversas. Por essa razão, a expressão de Afetividade nos chats observados possui mais instâncias de emoticons e de expressões menos convencionais de emoções. Nos fóruns, esse aspecto é detectado, majoritariamente, nas 
expressões de agradecimentos à resposta ou explicação enviada redigidas de forma convencional e sinalizando maior polidez.

Por outro lado, as duas ferramentas apresentam quantidade semelhante de manifestações de vulnerabilidade, sempre referentes às dificuldades, dúvidas e preocupações dos alunos para com as tarefas, conteúdos, funcionalidades e ferramentas do ambiente de aprendizagem. Similarmente, verifica-se que, nos dois gêneros de discussão, os recursos lingüísticos denotadores de intensidade (categoria "Força") são amplamente usados - advérbios de intensidade, termos de comparação, e sufixos diminutivos, por exemplo.

Quadro 3 - PS no Curso CEII: Pistas textuais indicadoras de Interatividade

\begin{tabular}{|c|c|c|}
\hline INDICADORES & EXEMPLOS FÓRUM & EXEMPLOS CHAT \\
\hline $\begin{array}{l}\text { Uso de recurso } \\
\text { do programa ao } \\
\text { invés de iniciar } \\
\text { nova discussão }\end{array}$ & $\begin{array}{l}\text { (uso do recurso do programa e início de novas } \\
\text { discussões) }\end{array}$ & $\begin{array}{l}\text { (uso do recurso do programa e } \\
\text { início de novas discussões) }\end{array}$ \\
\hline $\begin{array}{l}\text { Referência direta } \\
\text { a postagens de } \\
\text { outros }\end{array}$ & $\begin{array}{l}\text { Achei interessante essas dicas / Também achei } \\
\text { estranho / Não fui eu quem perguntou / Acho } \\
\text { que tem a ver com a pergunta da (...), } \\
\text { respondida mais acima / Tenho dúvidas } \\
\text { semelhantes / lendo as contribuições no fórum } \\
\text { / Penso que a afirmação da (...) foi referente a... } \\
\text { / gostaria de apoiar esta idéia }\end{array}$ & $\begin{array}{l}\text { não entendi direito isso / tb } \\
\text { entendi assim / o material que tu } \\
\text { postou }\end{array}$ \\
\hline $\begin{array}{l}\text { Cópia e colagem } \\
\text { de postagens de } \\
\text { outros }\end{array}$ & (Não encontradas) & (Não encontradas) \\
\hline $\begin{array}{l}\text { Perguntas } \\
\text { endereçadas a } \\
\text { colegas ou } \\
\text { tutores }\end{array}$ & $\begin{array}{l}\text { como faço? / Estou correta? / o sinal é } \\
\text { necessário? / Seria isso? / (...) tem que ser } \\
\text { daqueles postados? / tem de ser em itens } \\
\text { separados (...)? / O que fazer? / como eu faço? } \\
\text { / Poderias explicar?? / Preciso publicar algo? }\end{array}$ & $\begin{array}{l}\text { Alguma novidade? / poderia fazer } \\
\text { um teste para mim? / como assim } \\
\text { em cima de que? / eu o q? / como } \\
\text { vai ser a prova? / como assim em } \\
\text { cima de que? / Viu qual é a } \\
\text { resposta? }\end{array}$ \\
\hline $\begin{array}{l}\text { Comentários } \\
\text { positivos acerca } \\
\text { de mensagens de } \\
\text { outros } \\
\end{array}$ & $\begin{array}{l}\text { Ótima explicação / Muito bom colega! / } \\
\text { Interessante o seu comentário... / Boa a tua } \\
\text { iniciativa / Gostei muito do comentário de... }\end{array}$ & ----- \\
\hline $\begin{array}{l}\text { Concordância } \\
\text { com comentários } \\
\text { de outros }\end{array}$ & $\begin{array}{l}\text { Concordo plenamente colega! / Concordo } \\
\text { plenamente com a resposta da (...) / Concordo } \\
\text { contigo / Eu tb acho / Concordo parcialmente }\end{array}$ & $\begin{array}{l}\text { Isso! / siiim / concordo, colega / } \\
\text { também concordo contigo / sim } \\
\text { claro / exatamente }\end{array}$ \\
\hline
\end{tabular}

O mapeamento dos critérios discursivos referentes à Interatividade mostra que os fóruns possuem maior número de referências explícitas a comentários feitos por outro participante, e perguntas feitas aos tutores e colegas solicitando esclarecimentos e manifestando preocupações e dúvidas. Da mesma forma, são encontrados, nos fóruns, vários exemplos em que os sujeitos fazem comentários positivos sobre postagens de outros, o que expressa e reforça o sentimento de pertencimento no grupo. Diferentemente, não foram encontradas instâncias desse tipo nos 5 chats analisados.

Devido a seu aspecto assíncrono, o fórum permite que o usuário poste perguntas e respostas de forma mais elaborada e contundente. Nos eventos observados, as 
postagens nos chats são mais diretas, compostas por frases bastante curtas e, frequentemente, inacabadas.

Quadro 4 - PS no Curso CEII: Pistas textuais indicadoras de Coesão

\begin{tabular}{|l|l|l|}
\hline \multicolumn{1}{|c|}{ INDICADORES } & \multicolumn{1}{|c|}{ EXEMPLOS FÓRUM } & \multicolumn{1}{c|}{ EXEMPLOS CHAT } \\
\hline $\begin{array}{l}\text { Dirige-se aos } \\
\text { outros pelos } \\
\text { próprios nomes ou } \\
\text { vocativos }\end{array}$ & $\begin{array}{l}\text { Olá profe / Professora, veja se entendi / Ok, } \\
\text { profe! }\end{array}$ & $\begin{array}{l}\text { professor, fiquei insatisfeita... / } \\
\text { ok amiga .... / Alguém pode me } \\
\text { ajudar? / Olá pessoal / Tutoras e } \\
\text { colegas!! }\end{array}$ \\
\hline $\begin{array}{l}\text { Dirige-se ou } \\
\text { refere- se a } \\
\text { pessoas ou fatos } \\
\text { usando pronomes } \\
\text { inclusivos }\end{array}$ & $\begin{array}{l}\text { Sua colaboração foi importante para mim / } \\
\text { nós também precisamos nos atualizar }\end{array}$ & $\begin{array}{l}\text { Ei (...), tu acessas os } \\
\text { questionários? / e vcs devem } \\
\text { estar / queria ver se vc sabe... / } \\
\text { devemos ouvi-la então / nos } \\
\text { atrapalha / Se todos estão } \\
\text { reclamando / mais fácil para os } \\
\text { nossos alunos }\end{array}$ \\
\hline $\begin{array}{l}\text { Termos de } \\
\text { sociabilidade e } \\
\text { polidez }\end{array}$ & $\begin{array}{l}\text { Abraços e boa sorte / Grande abraço!/ Oi! / } \\
\text { olá /bjos / Abrs / Bom estudo a todos! / } \\
\text { Atenciosamente / []s. }\end{array}$ & $\begin{array}{l}\text { Olá colegas! / oii! / Tdo bem? / } \\
\text { boa noite!! / abraços / estou } \\
\text { indo... / ateh sábado / } \\
\text { buonanotte / bom findi! }\end{array}$ \\
\hline
\end{tabular}

Ao contrário das categorias referentes à Interatividade, o mapeamento das marcas de Coesão mostra maior número de ocorrências nos 5 chats do que nos 3 fóruns selecionados no estudo. Como é típico nesses ambientes de interação, os usuários sentem-se à vontade para entrar e sair, resultando em amplo uso de expressões de cumprimento e despedida, além do uso constante de nomes próprios e vocativos. Por se tratarem de atividades eletivas, os participantes parecem usar esses espaços como um local de encontro onde podem esclarecer pequenas dúvidas ou apenas estarem juntos sem maior comprometimento para com os conteúdos do curso.

Um aspecto importante neste levantamento é o fato de que, em português, as desinências verbais dispensam o uso do pronome pessoal, exceção feita nos casos em que houver ambigüidade de sentido. Isso significa que o critério de coesão em que os interlocutores usam pronomes pessoais para se dirigir ou referenciar os demais ou fatos envolvidos na discussão pode apresentar um número significativamente menor do que em outro idioma. Nos fóruns e chats analisados, encontram-se vários exemplos que ilustram esse recurso da língua portuguesa, tais como: clique, falei, disse (eu / você / ele / ela), envie,precisamos, lembre-se.

Considerando o exposto, pode-se afirmar que ambas as ferramentas de interação usadas na disciplina INF010 do curso apresentam sinais de presença social suficientes para demonstrar que os sujeitos utilizam os recursos lexicogramaticais da língua não só para se mostrarem mais presentes em ambientes virtuais, como também suscitarem o envolvimento de seus pares nas atividades de aprendizagem.

\section{Considerações Finais}

O artigo apresentou um estudo qualitativo em que se verificou o grau de presença social em chats e fóruns numa disciplina ministrada na modalidade à distância. O estudo de presença social nessas ferramentas verificou os aspectos afetivos, interativos e coesivos, como propostos por Rourke e colaboradores (2001). A esses, o modelo de análise usado 
neste trabalho acrescentou a categoria "Força" indicadora de intensidade e quantidade encontrada nos estudos de Martin e White (2005).

O grau de presença social (PS) é um indicativo de como os sujeitos interagem entre si e com o ambiente virtual de ensino e aprendizagem. Da mesma forma, a PS é tida como relevante no desenvolvimento de relacionamentos e na promoção e fortalecimento de sentimento de pertencimento no ambiente. Devido à ausência dos recursos de expressão existentes na interlocução presencial, as comunicações baseadas em texto apresentam signos lingüísticos diferenciados, característicos dos gêneros textuais digitais e indicativos do grau de afetividade e interação entre os participantes.

O levantamento feito nos chats e fóruns da disciplina INF010 do CEII mostrou que, nesse contexto, não existem diferenças significativas entre as duas ferramentas no que se refere ao uso de pistas lexicais indicativas de PS. Do ponto de vista do uso da língua, entretanto, observou-se que os chats apresentam uma quantidade maior de marcas da fala oral, atestando o registro coloquial e informal comum nesse gênero do discurso eletrônico.

A pesquisa em que este estudo se insere pretende ampliar o levantamento textual nas demais disciplinas do CEII de forma a ter um corpus expressivo de pistas discursivas de PS e, posteriormente, poder processá-las num programa de Mineração de Textos. O objetivo deste procedimento é ter um software de diagnóstico de PS acoplado a um AVEA como ferramenta auxiliar nas atividades de tutoria.

\section{Notas}

1.URL: <http://www.inf.ufrgs.br/informatica-uab>.

2.São Sepé, Jaguarão, Novo Hamburgo, Sapiranga e Serafina Correa.

3.No momento, (outubro 2010), o curso possui cerca de 130 alunos ativos.

\section{Referências}

BERCHT, M. Em direção a agentes pedagógicos com dimensões afetivas. Tese de Doutorado. Programa de Pós-Graduação em Computação. Instituto de Informática. Universidade Federal do Rio Grande do Sul. Porto Alegre: 2001.

BIOCCA, F.; HARMS, C.; BURGOON, J. K. "Toward a more robust theory and measure of social presence: Review and suggested criteria”. Presence: Teleoperators \& Virutal

Environments, v. 12, n.5, 2003. p. 456-80.

GARRISON, R. An analysis and evaluation of audio teleconferencing to facilitate education at distance. In American Journal of Distance Education, v. 4, n. 3, 1990. p. 13-24.

. "Critical thinking and adult education: a conceptual model for developing critical thinking in adult learners". In International Journal of Lifelong Education, v.10, n.4, 1991. 
GUNAWARDENA, C. "Social Presence Theory and Implications for Interactive and Collaborative Learning in Computer Conferences". In International Journal of Educational Telecommunications, v. 1, n. 2/3, p. 147-166. 1995.

LONGHI, M.; BEHAR, P. A.; BERCHT, Magda. A busca pela dimensão afetiva em ambientes virtuais de aprendizagem. In BEHAR, P. A. Modelos pedagógicos em Educação a Distância. Porto Alegre: Artmed, 2009.

LOWENTHAL, P. "The evolution and influence of social presence theory on online learning". In KIDD, T.T. (org.). In Online education and adult learning: New frontiers for teaching practices. Hershey, PA: IGI GLOBAL, 2009.

MARCUSCHI, L.A.. (2004) "Gêneros textuais emergentes no contexto da tecnologia digital". In: ; XAVIER, A. C. (orgs.). Hipertexto e gêneros digitais: novas formas de construção de sentido. Rio de Janeiro: Lucerna.

Paulo: Cortez, 2001.

Da fala para a escrita: atividades de retextualização. 2 ed. São

MACKEY, K.M.; FREYBERG, D. L.'The effect of social presence on affective and cognitive learning in an international engineering course taught via distance learning". In Journal of Engineering Education. v.99, n.1, p. 23-34. 2010.

MARTINEZ, M. "High attrition rates in e-learning: challenges, predictors, and solutions". In Learning Solutions e-Magazine, jul. 2003.

MARTIN, J. R.; WHITE, P. R. The Language of Evaluation: appraisal in English. London: Palgrave/Macmillan, 2005.

OTHERO, G. A. A língua portuguesa nas salas de bate-papo: uma visão lingüística de nosso idioma na era digital. Novo Hamburgo: Edição do Autor, 2002.

PALLOFF, R.; PRATT, K.. O aluno virtual: um guia para trabalhar com estudantes on-line. Porto Alegre: Artmed, 2004.

Construindo comunidades de aprendizagem no

ciberespaço. Porto Alegre: Artmed, 2002.

ROURKE, L; ANDERSON, T.; GARRISON, D.A. E ARCHER, WALTER. "Assessing social presence in assynchronous text-based, computer conference". In Journal of Distance Education, v.14, n.2, 2001.

SHIH, L.; SWAN, K. "Fostering social presence in asynchronous online class discussions. In Proceedings of the 2005 Conference on Computer support for collaborative learning. Taipei, Taiwan, 2005. p. 602-6.

SHORT, J.; WILLIAMS, E.; CHRISTIE, B. The social psychology of telecommunications. London: John Wiley \& Sons, 1976. 
WALTHER, J.B. "Interpersonal effects in computer-mediated interaction: relational perspective". In Communication Research, v.19, n.1, 1992. p. 52-90.

Computer-Mediated Communication: Impersonal, Interpersonal, and Hypersonal. In Communication Research, v. 23, n. 1, 1996. p. 3-43.

WIVES, L. K. Um estudo sobre Agrupamento de Documentos Textuais em Processamento de Informações Não-Estruturadas Usando Técnicas de Clustering. Dissertação de Mestrado. Instituto de Informática. PPGC-UFRGS. Porto Alegre, 1999. 